\title{
Q Linguagens
}

\section{APRESENTAÇÃO}

A revista Linguagens \& Cidadania, nessa edição especial, dedica-se à socialização das pesquisas em andamento no Programa de Pós-graduação em Letras da Universidade Federal de Santa Maria, cujos trabalhos foram apresentados e selecionados a partir do $I$ SETEDI - Limiares: Letras no contexto das humanidades, I Seminário de Teses e Dissertações do PPGL-UFSM. O evento teve como objetivo, com a promoção de um espaço de provocação ao debate entre as diversas áreas das humanidades, possibilitar ao aluno do PPGL, como agente do processo, a visão abrangente do campo em que se inserem a Linguística e a Literatura e suas conexões com as diversas epistemologias sociais, favorecendo, assim, o aprofundamento e a ampliação das perspectivas de investigação.

A proposta de realização do I SETEDI - Limiares: Letras no contexto das humanidades nasce como recurso às necessidades manifestadas pelos alunos do Programa de Pós-Graduação em Letras com relação à compreensão e ao trânsito de conhecimentos no âmbito da área das humanidades. Por diversos motivos, sejam históricos, sociais ou culturais, a formação universitária vem apresentando carências devido à extrema especialização e, consequentemente, à falta de contato entre as áreas, embora a universidade seja por excelência lugar onde os processos de pesquisa preveem o uso de abordagens e metodologias que abarquem, ampliem e façam dialogar os mais variados campos do conhecimento.

Perante as condições históricas que vivemos, com a polarização do pensamento e os retrocessos no âmbito da ciência e, sobretudo, da educação, promover o espaço para o debate e incentivar a disseminação do conhecimento são compromissos da universidade que se tornam, hoje, mais do que fundamentais. Nesse sentido, a área de Letras, enquanto lugar crítico de produção do conhecimento que se erige nas fronteiras, é capaz de trazer respostas epistemológicas ao presente, uma vez que as linguagens disseminam porque o indizível pode ser simbolizado.

Convém ressaltar que os artigos aqui reunidos foram selecionados para representar um número bem mais amplo de pesquisas, as quais se encontram em processo de 


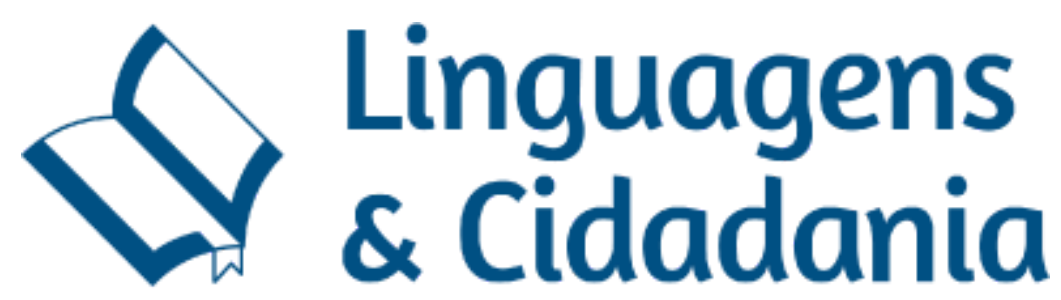

desenvolvimento no PPGL-UFSM. Essa seleção foi feita sem perder de vista um dos principais objetivos do evento, a intersecção e o diálogo entre as áreas das humanidades, propósito que foi contemplado desde a seleção de convidados para as conferências até o planejamento das apresentações nas salas de comunicações. Dessa forma, com abordagens teóricas e metodologias diversas, partindo dos universos da Linguística e da Literatura, os artigos transitam pelo campos da História, da Filosofia, da Sociologia e da Educação, abarcando temas como violência, opressão e silenciamentos, exílio, resistência e decolonialidade, conflitos de poder, memória e enunciação e disciplinarização das línguas indígenas.

No primeiro artigo, intitulado "Identidade e a representação do feminino em Jane Eyre: razão, emoção e opressão", Karina Kurtz analisa o romance autobiográfico Charlotte Brontë, e, atentando para a construção da personagem que se calca no puritanismo e no moralismo religioso, aponta as formas de repressão na era vitoriana. A partir de pressupostos filosóficos, esse artigo leva a compreender a oscilação entre a intuição e os conceitos éticos que estão na base de formação de Jane.

Em "Violência e memória corporal como dispositivo de (re)organização de subjetividades na literatura de Herta Müller", Adriana Yokoyama e Rosani Umbach perscrutam as memórias da violência ditatorial e seus efeitos em $O$ Compromisso (2009), Fera d'alma (2013) e A raposa já era o caçador (2014), narrativas da romena Herta Müller. A partir dos conceitos de Hannah Arendt e Aleida Assmann, o artigo evidencia as marcas de resistência e as formas de expurgação perante a violência e suas formas de inscrição.

"A mulher como o outro: uma história de deslegitimação e silenciamento", de autoria de Camila Cargnelutti e Anselmo Peres Alós, problematiza as estruturas de construção dos processos históricos que promovem as relações desiguais e formas de dominação por meio de estratégias de silenciamentos da mulher. Com base em Beauvoir, Irigaray, Millet, Moi e Scott, apresenta-se uma contextualização histórica e algumas das ferramentas de instauração do poder masculino, que trabalham para subjugar a mulher ao lugar de outro. 
Em “A fita de Möebius ou a experiência infinita: desconstrução e descolonialidade na obra de Carola Saavedra", Ilse M. R. Vivian analisa o romance Com armas sonolentas (2018), colocando em relação os aportes teóricos da Teoria da Narrativa, dos Estudos Culturais e dos Estudos Decoloniais. $O$ artigo explicita os movimento de (re/des)construção da memória e suas aproximações com as epistemologias chamadas Decoloniais, proposta de alteridade construída nas relações de dominação dos tempos modernos e de desenvolvimento dos capitalismos globais, os quais produziram pela colonialidade do poder a subalternização do saber e da vida social.

Parte da tradução da obra inédita de uma das escritoras espanholas esquecidas pela história, Luisa Carnés (Madrid, 1905 - México, 1964), é o objeto de estudo de “A trajetória de exílio de Luisa Carnés", de Ana Paula Cabrera. Com o objetivo de criar um método de tradução para a obra da autora que privilegie a trajetória de exílio proposta pelo material, Ana Paula resgata e apresenta parte da obra, De Barcelona a la Bretaña francesa (1939) e El eslabón perdido (1957). Depois de quase cinquenta anos de esquecimento, ao iluminar o passado, o resgate dessa obra de natureza testemunhal, conforme afirma Ana Paula, não só traz ao presente novos elementos literários, como também redimensiona a compreensão histórica e social da vivência do exílio e suas repercussões na atualidade.

O sexto artigo, “A Revolução Francesa: análise do poema de William Blake sob a luz do novo historicismo", de autoria de Odon Bastos Dias e Enéias Tavares, analisa a forma como o poeta inglês orquestra em sua obra os acontecimentos da revolução e os organiza numa narrativa lírica e revisionista. A partir do aporte teórico proposto pela corrente do Novo Historicismo, são observadas as relações entre o ficcional e o histórico, que resultam em imagens carregadas de simbolismo.

Também de uma perspectiva comparatística, em "Legitimidade monárquica: o conflito entre poder real e moral em Ricardo II e Ricardo III', Wladimir D'Ávila Uszacki analisa o poder monárquico e o conflito moral e material do fim do período medieval e do início do early modern inglês. Com base em textos de ciência política e de teologia que tematizam o poder e a autoridade monárquica, o artigo mostra como William Shakespeare apresentou uma releitura da história sob a visão dos dois monarcas. 


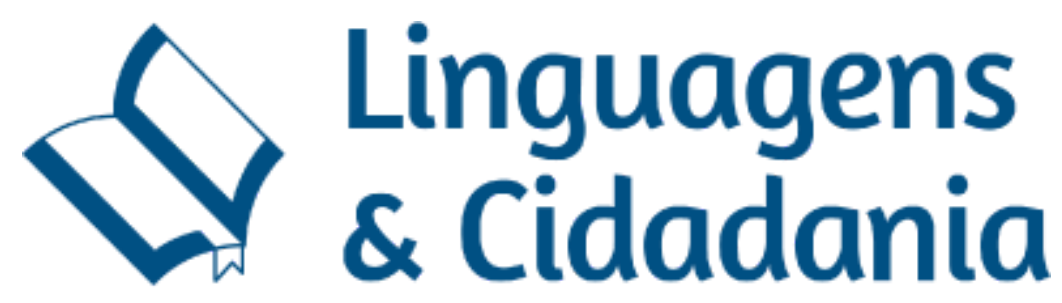

Ainda sob viés histórico, mas agora com o foco sobre a modernidade, "Felippe D’Oliveira e as ações conspiratórias da Revolução de 1930" tematiza a figura controversa e plural do poeta fluminense do início do século XX e sua participação no grupo conspiratório Tríade Indissolúvel, cuja articulação culminou na tomada do poder pelos parlamentares integrantes da Aliança Liberal, liderados por Getúlio Vargas. De autoria de Lucas Zamberlan e Pedro Brum Santos, o artigo analisa o papel desempenhado por Felippe D’Oliveira no contexto da Revolução de 1930 e como se relacionam o tema político e sua obra.

Em "Estudo do gótico nos romances $O$ crime do padre Amaro, O primo Basílio e Os maias, de Eça de Queiros", Xênia Amaral Matos mostra como o gótico é incorporado nos textos ecianos. Em sua análise, com base no aporte teórico de Curtius, Barthes e Bouttes, a autora privilegia a categoria do espaço, a loci horribiles, para evidenciar a tradição gótica presente nos romances, como os topoi da casa mal-assombrada, do fantasmagórico e do amaldiçoado.

Francielli Borges, em "Ler a palavra e a imagem nos romances de Graciliano Ramos e nas capas de Tomás Santa Rosa, propõe lançar um novo olhar sobre a recepção da obra de Graciliano Ramos a partir da comparação da crítica sobre ambos os artistas, Graciliano e Tomás, bem como sobre a figuração das personagens e suas formas de atuação no enredo. Além disso, a autora propõe a reinterpretação do texto literário à luz das imagens produzidas por Santa Rosa.

Da imagem à enunciação e o inverso. Em "Retratos da escrita: espaços de enunciação, memória e língua de imigração”, Rejane Carpenedo propõe pensar a língua de imigração alemã na perspectiva da Semântica do Acontecimento (Guimarães, 2002) para pesquisar em quais espaços de enunciação circula a escrita alemã e que sentidos políticos e históricos thes são subjacentes. $\mathrm{O}$ artigo apresenta os primeiros subsídios do estudo, que está em desenvolvimento no município de Novo Machado, região noroeste do Rio Grande do Sul, espaço colonizado por imigrantes alemães e italianos.

"Reflexões acerca de uma história da disciplinarização de Línguas Indígenas no Ensino Superior brasileiro", de Bruna Cabrera, tematiza aspectos da realidade de formação indígena. Com base em arquivo constituído por documentos relativos à disciplinarização 


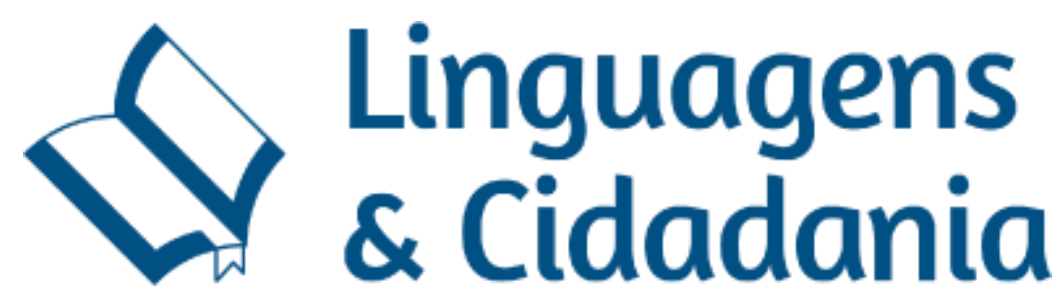

de Línguas Indígenas no Ensino Superior, a autora propõe-se a explicitar como ocorre o processo de institucionalização e disciplinarização de Língua Indígena no Ensino Superior com foco na formação de professores e também que efeitos de sentido são produzidos durante a construção do conhecimento linguístico e preparação didática.

Por fim, Alessandra Rocha e Thaís Corsino, em "Ensino de língua inglesa para a terceira idade: a oferta dos cursos de extensão universitária no Brasil", apresentam o relato da atividade proposta pelo Projeto Integrado de Práticas Educativas: o ensino de Língua Inglesa para adultos da Terceira Idade, oferecida pelo curso de Letras da Universidade de Uberlândia. A partir de levantamento feito em todas as universidades do Brasil sobre a oferta de cursos de extensão universitária para a terceira idade, as autoras observam as fragilidades do sistema, tanto com relação à distribuição geográfica, quanto às metodologias empregadas. Com a atenção voltada à expansão do envelhecimento no país, as autoras analisam as possibilidades de aprendizado de qualidade para a terceira idade, meios que permitam a interação, a exteriorização de seus pensamentos, sentimentos e emoções e ampliem sua capacidade de comunicação e linguagens.

Desejamos a todos uma boa leitura!

Organizadores

Prof. Dr. Ilse M. R. Vivian

Prof. Dr. Cristiane Florek

Prof. Dr. Lucas Zamberlan 